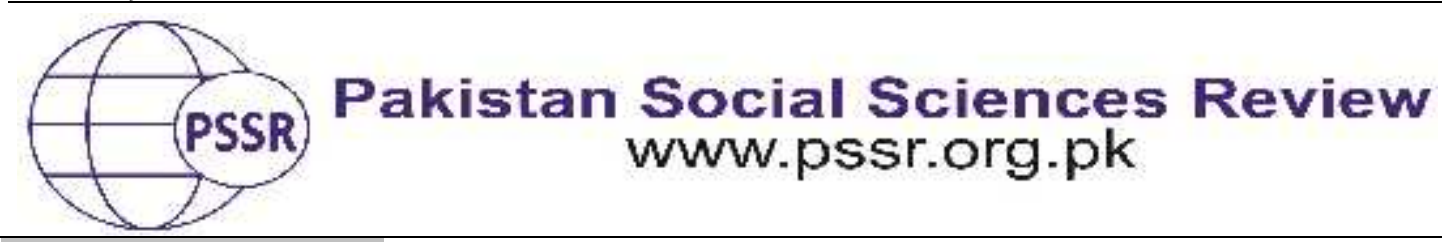

RESEARCH PAPER

\title{
On Being and Becoming Beautiful: The Social Construction of Feminine Beauty
}

\author{
Dr. Saadia Abid ${ }^{1}$ Nagina Liaquat 2 Dr. Aisha Anees Malik ${ }^{3}$
}

1. Assistant Professor, Department of Anthropology, Quaid-i-Azam University, Islamabad, Pakistan

2. M. Phil, Department of Anthropology, Quaid-i-Azam University, Islamabad, Pakistan

3. Assistant Professor, Centre of Excellence in Gender Studies, Quaid-i-Azam University, Islamabad, Pakistan

\begin{tabular}{|c|c|}
\hline PAPH & S \\
\hline $\begin{array}{l}\text { Rece } \\
\text { Apri } \\
\text { Acce } \\
\text { May } \\
\text { Onli } \\
\text { May }\end{array}$ & $\begin{array}{l}\text { An abstract concept yet widely pervasive across time and space, } \\
\text { beauty, remains a matter of core concern in many cultures. Just } \\
\text { as standards of social status that are achievable, beauty } \\
\text { standards can be sometimes partially at others wholly achieved } \\
\text { through the use of different methods and techniques. Being }\end{array}$ \\
\hline $\begin{array}{l}\text { Key } \\
\text { Femi } \\
\text { Socia } \\
\text { Inter } \\
\text { Exter } \\
\text { Beau }\end{array}$ & $\begin{array}{l}\text { beautiful. In either case, the } \\
\text { cultural standards and norms. } \\
\text { with femininity. Based on } 23\end{array}$ \\
\hline onding & $\begin{array}{l}\text { understood as a bipartite concept with internal beauty referring } \\
\text { to the personality traits and external to body features. Feminine } \\
\text { beauty can be enhanced through cosmetics, clothing and } \\
\text { ornamentation. The study concludes that feminine beauty is a } \\
\text { socially constructed and highly fluid phenomenon. Even when } \\
\text { we manage to achieve somewhat standardized general } \\
\text { framework of certain beauty attributes, there is a great } \\
\text { variability within these attributes. }\end{array}$ \\
\hline
\end{tabular}

Introduction

In this article we explore the concept of beauty as a socially constructed phenomenon. We find the age old ubiquitous adage "Beauty lies in the eyes of the beholder", also as reflective of a constructionist approach. It can easily be deduced that beauty does not have an objective reality rather it is a subjective experience; perceived and inferred by the observer. We extend this argument even further and contend that both the beholder's gaze as well as beauty as a concept is socially constructed. The beauty standards set by the society are internalized by its members who then strive to "beauty up" while the beholder's eye is enculturated to gauge beauty with the set parameters that are learnt. One of the reasons we do not take 
beauty as given, is because what counts and constitutes as beautiful is relative to time and space. Equally important is the fact that beauty as a concept is universal, exists in all societies; historical, prevalent since times unknown; and gendered, primarily associated with women.

Of the various aspects concerning femininity, beauty remains the most elusive and not a sufficiently theorized concept. The wide range of cosmetic products and mushrooming of salons and parlors are evidence of society's obsession with feminine beauty and perhaps also of women's internalization of the social standards of it. A relentless pursuit for beauty is being followed. Given the constructionist, contextual and gendered dimension of beauty, this paper sets to explore the definition of feminine beauty, its constituent features and beauty standards with a particular focus on women.

\section{Literature Review}

Beauty, as a concept, perceived, practiced and experienced, is not given. Several studies establish beauty as a socially constructed phenomenon (Steinberg, 2015) (Blood, 2004) (Wolf, 2013). Since ancient times, the body has been a site of constant work, to be redesigned in culturally appropriate ways.(Reischer \& Koo, 2004). This redesigning and reshaping renders identity to the body and the person; a fit body, a well-maintained body, a smart person etc. Of the various facets of body and identity, beauty as a concept holds and key position. The preferences of the person vis-à-vis body work are also reflective of and influenced by one's social class. Gimlin (2001) argues that "style and appearance preferences display a complex social identity that is both relevant for and shaped by class identity" (Gimilin, 2001, p. 23)

However, the gender dimension of beauty (Black \& Sharma, 2001)remains central; with feminine beauty as the most dominant facet. There is no society that has not set normative standards for feminine beauty. The patriarchal system has a major role to play in the construction of an ideal feminine body. A close link between "doing beauty" and "doing femininity" can be observed in several societies. Women's conformity to the conventional standards of beauty are not only "accepted" but are also "expected" of women (Lazar, 2011, p. 37). Non-compliance would be a deviation and may have repercussions. The "beauty myth" created by the patriarchal society keeps women constantly occupied with the predicament of how to look (Wolf, 2013). The standards established are definitive as well as evaluative. Women draw their self-identity, self-conception and indulge in selfjudgment through this model of beauty. As a result, the physical self becomes the core of her self-conception, argues Tseelon. And a positive relationship between physical attractiveness and self-concept throughout the lifespan is reported consistently in her study on the "ideology of beauty" (Tseelon, 1993). Women internalize the standards and work to achieve the best possible. On the other hand there are studies that view beauty as therapeutic: the beauty salon may be seen as the site of both compliance with, and escape from, a feminine ideal (Black \& Sharma, 2001). 
The present study is part of larger project that explores i) an understanding of feminine beauty as a socially constructed phenomenon; ii) the transformation of the concept of feminine beauty over time iii) and the role of beauty parlors in cultivating and propagating beauty standards. However, this particular paper focuses only on the definition, constitutive elements and parameters of feminine beauty in a patriarchal system. In doing so it also highlights the normative, at times, prescriptive nature of conventional standards of feminine beauty.

\section{Materials and Methods}

Using qualitative research methods this descriptive study aimed to investigate the normative understanding of "feminine beauty". A total of 23indepth interviews were conducted for the purpose. The interview style was more like a guided conversation led by the key research question about the definition, constituent features and normative standards of beauty as perceived by the respondents. All interviews were conducted in Rawalpindi district and with women both in their domestic space and beauty parlors where they have come for beauty services. Data saturation was taken as an indication to cease the interview process and initiate analysis. The content of the interviews was carefully assessed and analyzed using thematic analysis. The dataset was read and reread to arrive at a systematic understanding and to identify relevant themes. Following ethics of the research, informed consent was obtained before conducting an interview. Tape recording was done post respondents due permission. Following questions were addressed through analysis: What is beauty in general and feminine beauty in particular? What are its constitutive elements? And what are the parameters and social standards set for its constitutive elements? Respondents' anonymity was preserved by expressing their responses without disclosing their identities. The verbatim responses of respondents are presented where necessary and have been italicized to keep them separate from the running text of the article.

\section{Beauty: definition and evolution of the concept}

When asked about beauty as a general concept, the most common responses include, jo aankh bhaai (anything that pleases the eye); purlutf (pleasant); jo khushgawar ahsaas de(that which is aesthetically pleasant). In most of the discussions on beauty, an inevitable and swift shift from beauty as a generally concept to beauty as one closely linked to femininity was found particularly interesting. Often even before the researcher would ask specifically about feminine beauty the respondent would lead the discussion towards it. This reveals how closely the idea of beauty is linked to femininity. On repeating the question and making the respondent aware that it is about "beauty" and "beautiful" as general concepts, some of them reiterated this analysis. Oh but you know it is always a woman who is beautiful, you seldom hear of a man as such, a respondent justified shyly. On being asked what constitutes beauty and beautiful, a respondent informed that the word beautiful creates an image in mind of fair skin, big and colored eyes, long hair, pink cheeks, attractiveness etc. etc.. And while the respondent apparently may seem to have replied in gender neutral terms, 
reference to feminine beauty is obvious. Another equally interesting notion is the bipartite understanding of beauty as something external and physical on one hand, and internal and moral on the other. The former is tangible with intangible consequences while the latter is intangible shown to have tangible imports. A symbolic as well as functionalist perspective is obvious in the delineation of both types. Starting from the basic understanding of "feminine beauty" as a bipartite concept, the section further explains what we call the beauty enhancers: cosmetics, sartorial enhancers and ornaments and accessories as concomitant to the external beauty.

\section{Internal Beauty}

Internal beauty is the real beauty of women is a statement that echoes across all the interviews. When asked what is internal beauty, in most of the cases the first reference is made to is acha ikhlaq (good manners) and achi seerat (good nature).On further probe, it was revealed that what constitutes this type of beauty are certain personality traits. Among which, good manners, intelligence, innocence and a pure soul are identified as the main traits. Not only do they believe in internal beauty as real beauty but also as those women who are internally beautiful are the real women. Often the statements defining internal beauty are followed by evaluative interrogative statements as if to seek validation or perhaps to suggest an evaluation: Those women who have no manners what is the benefit of their beauty? What benefit is her fair complexion if a woman is disobedient? This also entails weighing in terms of what is more important? The women lamented that in present times the focus has shifted to external beauty, which they believe is superficial, transient and even artificial. At the same time, the onus of this shift is placed on society and not on women, the former super imposing certain standards and compelling women to adopt to them. What is it that society looks for in a woman? To this a common response is: People do not focus on internal beauty, the focus is rather on external beauty of woman, fair complexion, physical attraction, long hair, beautiful eyes etc.

What was striking was a constant reference to religion and morality when speaking of internal beauty. It is this type of beauty, it is believed, that religion ordains to cultivate. The society's emphasis on external beauty is taken in opposition to religious decree.

God sees the internal beauty of a woman but society forces her to concentrate on the artificial beauty

Modernity in general alongside media, fashion and cosmetic industry, are all pointed out as playing a role in setting of such societal standards. The degree to which these factors influence women, however, greatly varies. Closely linked to this is the comparison between those who do not or only partially follow or conform to these normative societal demands versus those who have supposedly given in to modernity. 
It is the time of the modernity and society generally approves only fashionable and modern. Peoples are deriding simple woman. They think of her as senseless, a dupe, of lesser intelligence. There's no harm in following fashion and modernity but some women's are extra conscious about these things. They opt for what is latest and modern tools and techniques even those that are not acceptable in our society and religion. Also they would just not think if this fashion suits her or not.

An interesting dimension of this internal beauty is cleanliness; the purity of soul and a neat outlook. Again we find a reference to religion here. Faith demands cleanliness, the high value attributed to it is evident from the fact that half the faith is about it. The purity of soul is explained in terms of purgation; free from lying, stealing, backbiting and other such moral impurities.

Neatness is the beauty of the woman because our religion also said cleanliness is half faith. If a woman takes care of her hygiene, wears neat beautiful dress and her heart is clean, she is beautiful. She doesn't speak lie. She has not a habit of back biting, exaggerating, making up stories, it means she is beautiful because beauty would reflect in her soul.

Internal feminine beauty is about feminine role performance. Real beauty of woman is that she looks after her home and children and not the artificial beauty, said one of the respondents. She further explained that while the society does focus on external beauty traits, internal ones have a greater and long-lasting impact on the personal life of a married woman.

Most of the peoples are attracted towards the external beauty of a woman, her facial features. It is wrong! The society should measure the beauty of a woman from her manners. Good attitude and personality form the beauty of a woman. If a woman is beautiful but disobedient and ill-mannered she would not lead a successful life, especially after marriage. Internal beauty is essential for successful married life.

Compensations are possible but only in case of external beauty which can be compensated by internal beauty, much more functional and moral, than aesthetic.

Artificial beauty cannot fulfill the lack of natural beauty. Real beauty of the woman is in her compassionate and empathetic nature.

Exception to this is a case where a respondent made reference to internal "beauty" of a man. She while explaining sincerity as an important feature of internal beauty narrates: My husband is good natured, he is sincere with me. I am also loyal to him. This is the beauty of our relationship. My husband is not handsome at all but he is sincere. He tries to provide for all that is needed by the family. I am very happy with him. It does not really matter how he looks from the outside, he is beautiful from the inside. She seemed excited during the interview and added that it is the first time I am speaking about this aspect of my married life, discussing about my husband's looks. What is reiterated in this explanation is conformity to gender role as an aspect of internal beauty; albeit this time it is about man's role. 
In a patriarchal social setup this pressure is also recognized as a gendered pressure; the standards for women's beauty are set, endorsed, reiterated primarily by men. Men look for external beauty than internal beauty. Here, media is quoted as the most influential medium shaping the perception of men. A specific sketch of an ideal woman is conceived by men through media led images of "beautiful" and "ideal" woman. They are then driven to find for themselves a partner similar to those shown in media. Most of the respondents disapproved this imaging of women. In some cases they hinted at focusing on the overall personality of the woman rather than just a few physical features.

A few respondents however, brought to light the dichotomy in conception of beauty. As mentioned earlier all the discussions on beauty are marked by an initial and first reference to internal beauty. Followed by an emphasis on the significance and importance of internal beauty. A few respondents find this emphasis as existing only at a theoretical level with contrary practices in real life. They believe that everyone, including women, only speak about internal beauty. But in practice, work more on enhancing the external beauty than internal beauty.

Another view where we found variation among the respondents concerns the evolution of the concept and practices. While some believed that in past women's focus was primarily internal beauty. Others do not see it as a change in emphasis on a certain type of beauty. Rather they view it as a difference in the use of material and methods for enhancing external beauty. The latter believed that women have shifted from more home based natural products to massively produced cosmetic and commercial products.

\section{External Beauty}

Having established a basic understanding of internal beauty we now shift our focus to external beauty. External beauty is physical; the attributes inevitably cited include facial features; skin tone (emphasis: fair skin as most preferred); skin clarity (emphasis: without blemishes/pimples/scars); eyes (size and colour; emphasis: big and coloured where coloured means blue, green, hazel, grey, light brown), nose (size; emphasis: small and narrow nose bridge), hair (quality, length, sometimes colour; emphasis thick, long, brown, light brown, blonde). Overall body structure is equally important with a preference for slim body. Followed by "beautiful" hands and feet (neatness, skin quality and skin tone). Height is another feature albeit rarely mentioned.Compensations are possible, for instance, a fair complexion may override other beauty standards.

The external beauty has the power to lead to an immediate impression. And although referred to as transient can be 1) enhanced and 2) maintained, both by appropriate care and cosmetic use. All the respondents have reported use of or at least a comprehensive awareness of cosmetics for hair, for skin (use of facial treatment, bleach for fair complexion); for body (using exercise, gym, tablets for sliming body, plastic surgeries); for eyes (used lenses); manicure and pedicure for hand and feet. For appropriate care, use of moisturizers for skin and oiling of hair 
have stood as the most common and significant upkeep traits. Here we find a to the link between beauty youthfulness. Clark's study on older women's indulgence in "beauty work" to defer their entry into a socially disadvantaged category of old women is enlightening in this context. (Clark, 2018)

Interestingly, when asked generally about conceptualizing beauty a clear distinction is made between inner and outer beauty with a tilt toward inner beauty. However, when specifically asked about external beauty, the enthusiasm was noteworthy. The elaboration is detailed. Similar to internal beauty, external beauty was also deemed as a "need" although for different reasons. In case of internal beauty reference to religion and morality were predominant; while the external beauty was shown to be a social demand for which social pressure is exerted. The respondents seem to have well internalized this pressure and consider it necessary to fulfill these requirements. They even show a sense of accomplishment when these social requirements are duly and appropriately met.

A functionalist perspective is obvious in delineation on both types of beauty, internal as well as external. External beauty also stood out as a status marker; women believed that a "beautiful" woman enjoys a better social status and receives more social attention compared to one who has "average" looks. Several benefits are associated with being beautiful; for instance, it is believed that in job market beautiful women fare better. Internal beauty is more about cultivation of the self. As against that external beauty is about "born" beautiful and "becoming" beautiful. A woman who has fair complexion, coloured eyes, and long hair is referred to as composite beauty. Speaking on the relationship between social status and outer beauty, a respondent explains:

Society demands beauty and not simplicity and good manners. Looks are noticed the first and foremost. Good manners, only later. A simple looking woman, simply dressed would catch attention of no one. Firstly, they look at your external side and only afterwards notice the internal, only after when they speak to you. Self-esteem, power and positions; all are associated with the external beauty of the woman.

For born beautiful we have listed the characteristics above. How does or can one "become" beautiful is what follows. Given their specific characteristics we have called them beauty enhancers. The three beauty enhancers, cosmetics, clothing and ornaments are discussed according to the preferential order deduced from analysis of the interviews.

\section{Cosmetics}

These include two types: simple, comprise of natural and herbal ingredients mostly readily available at home and are used for care purposes primarily. These include products for skin like ubtan (A powdered mixture of several herbs and natural ingredients used for cleansing and lightening of the skin), aloe Vera, ointments and masks prepared using honey, lemon, yoghurt, cream; hair products, 
several different kinds of oil, and henna; dandasa (tree peel from walnut tree)for whitening of teeth. Being natural, and without chemicals, these products it is believed to be innocuous with no side effects. Although primarily care products, they are assumed to have transformative potential. For instance, ointment prepared with honey and lemon is used with aim to bleach and lighten the skin tone using harmless products. Similarly, henna is considered to have dying and conditioning properties and is used for either or both purposes.

The second type is chemically produced cosmetic articles for commercial purposes and is available in the market for sale. Cosmetic industry is so widely known now with diverse and varied items being produced, advertised and sold for both personal and professional uses. We think it is of little use to enlist the products. However, what is important to note is that we find both care as well as "enhancers" in these. The products are either to be applied; such as, lipstick, nail colour and innumerable other items or are appendages, for instance, wigs, false lashes etc. The care products include those for maintenance (sunblocks, moisturizers), reversals (anti-ageing) and transformative (fairness creams).

\section{Sartorial Enhancers}

Next comes the sartorial concerns and preferences. It is believed that in order to be "presentable", one must pay attention to what one wears. Clothing is closely linked with personal image. The mushrooming of clothing brands has resulted in multitude of options to choose from on one hand, while, on the other also exerts a pressure to wear a brand. Women reported that branded clothes have become a necessity as well as a nuisance. They are now viewed as a status symbol. Younger women prefer to wear designer dresses, irrespective of high cost as they are perceived "fashionable". Wearing of simple and non-branded clothes is sometimes even considered as "embarrassing". For women, fashion in dress is particularly important. A few respondents confessed that it is difficult to be accepted in social circles if one is dressed out of fashion. In parties and on weddings, even during a common day to day activity, such as shopping, women prefer following updated fashion. They even ensure that hairstyle, cosmetics such as nail colour, lip colour, the colour of hand bag and shoes are according to their dress such is the significance of clothing.

Women's closet is well assorted, with separate, dresses for different occasions. There are casual dresses, semi-formal or party wear, and more embellished clothes for wedding ceremonies. What would people think if I wear out of fashion clothes? is a concern of many respondents. The category "people" is a general category, includes close relations, distant ones and even those who are not known at all (and whose opinion may never be known) for example, people in the market. Repetition of the dresses is also a matter of concern. Again here we find that portrayal of self-image is the guiding principle. What would people think if I repeat the same dress time and again? Why is even there a concern for a person's (people's) opinions that may never even be known? On probe, it was explained that society is judgmental about appearances. Society is referred to in anthropomorphic terms; having set standards, norms and values and an unceasing evaluative gaze. The self- 
image is assumed to be constantly being judged on the basis of how one looks and carries herself. To a simply dressed woman even the shopkeepers do not pay attention to and ignore her, says a respondent. Here again we find clothing, fashion and social status as intertwined. A simply dressed woman is often not considered as a potential buyer.

In a similar vein, respect is associated with better outward appearance achieved through sartorial features, the latter being a marker of social status. Khao man bhata, pehno jag bhaata (eat as your heart desires, wear what the society likes) is an idiom used to explain the importance of dressing up as per social norms and standards. A respondent explained that the idiom points to the fact that what is immediately visible is important and must be paid attention to.

Thus, clothing as per our respondents has become a tool to evaluate and reckon social status, as to whether the person deserves attention and interaction. A woman narrated that once when she went to a designer's shop in search for a formal party wear. The salesperson did not consider her as a client worth investing time. The reason she quotes is because she was clumsily dressed. However, feeling humiliated by their response, she switched to English (also a marker of social status) to claim the respect and attention she believed she deserved as a potential buyer. Another respondent reflects on the relationship between clothing, status, social hierarchy and consequent respect:

In today's world clothing reflects social status. Peoples estimate the status of each other from clothes. Rich are distinguished form the poor based on their dressing. If a woman wears fashionable, expensive clothes people think that she is very rich, she may or she may not be, but society perceives her status through such conjecture. The respondent hastily added but then good dress is the part of woman's respect.

From the interviews, it can be deduced that women sometimes consider societal emphasis on clothing and fashion as exaggerated. However, they also find an interest in clothing and fashion as a feminine interest. Who kon $c$ aurat ho gi jisay kapron ka shouq na ho ga (What kind of a woman she be who does not have an interest in clothing).

\section{Accessories and Ornaments}

In addition to clothing and fashion, ornamentation and the use of accessories are also important beauty enhancers. They are conceptualized in two dominant ways: as complimenting beauty; and as compensation for beauty. In the latter sense it is always high cost precious metal and/or stone jewelry for instance, jewelry made out of gold, platinum, diamond and other stones and pearls. Like branded dresses, the ornaments are status markers. Expensive ornaments are reflective of the wearer's affluent status. One of the respondents informed and particularly in the context of spouse selection that there are two things important while looking for a bride for 
one's son: how she looks and what she brings (as dowry). If she is "average" looking but comes from a rich background, her appearance will be overlooked.

However, most of the respondents stated that times have changed and with that also the interest in accessories and ornaments. Till recent past, it was considered almost obligatory for a married woman to wear gold ornament to show her marital as well as socio-economic status. In present times, the jewelry does not necessarily entail expensive jewelry. It rather refers to such items that are aesthetically pleasant to look at and compliment the dress of the person wearing the jewelry. Just as clothing is closely related to beauty; jewelry and accessories are linked with clothing. "Matching" is word that echoes frequently and repeatedly in all the interviews and during discussions on dress and jewelry/ accessories. The latter must "match" the former. How? Either as an aesthetically pleasant contrast or a combination; for instance, red against orange or blue combined with teal.

Another important word that requires deliberation is "over". One must never "over dress" or wear "over jewelry" etc. The closest proximate of this could be "exaggerated", "more than what is required", and "out of or not relevant to the context". Anything could be over a dress, a bag, shoes, lipstick etc. Over is perhaps the most difficult variable to comprehend. A related and equally complicated variable is "suit". This is a term that stands in opposition to "over" and like "over" is extremely difficult to delineate because what "suits" varies greatly. Wear what "suits" you. One my dye one's hair but only in a shad that "suits". And like "over", anything could (or could not) suit. While highly fluid and flexible, these terms and their understandings are cultural specific and socially constructed.

\section{Conclusion}

Beauty, as a concept, is not given rather is socially constructed. Similarly the emphasis on feminine beauty is a result of several social factors, patriarchal normative structure being the most important. Beauty standards vary greatly across time and space. A woman's self-image vis-à-vis beauty is informed by the definitions, values, norms and standards set by the society. These standards are widely pervasive, internalized, unquestioned and taken for granted by its members. The cultural assumptions are then coded in and represented by the body. Nonconformity are shown to have consequences. Here, we would like to reiterate three focal points that have emerged from the data i) Beauty is about being as well as becoming, hence, the use of beauty enhancers ii) There is a close connection between beauty and representation of the self iii) Whether ascribed or achieved beauty renders a sense of entitlement; a claim for respect and attention. What remains the most important finding is the fluidity and flexibility of the concepts made obvious through the possibility of compensation. One beauty feature may compensate for lack of another, for instance, a fair skin would compensate for absence of small and narrow bridged nose. In defining feminine beauty and delineating its constituent features we realized that only a broad generalized framework can be identified within which variations are influenced by class, age, gender and other social aspects. 


\section{References}

Black, P., \& Sharma, U. (2001). Men are real, Women are 'made up': beauty therapy and the construction of femininity. The Sociological Review, 49(1), 100-116. doi:10.1111/1467-954x.00246

Blood, S. (2004). Body Work: The Social Construction of Women's Body Image. New York, London: Routledge.

Clark, L. (2018). Women, Aging, and Beauty Culture: Navigating the Social Perils of Looking Old. Generations , 41(4), 104-108.

Gimilin, D. (2001). Body work: beauty and self-image in American Culture. Berkeley: University of California Press.

Lazar, M. (2011). The Right to Be Beautiful: Postfeminist Identity and Consumer Beauty Advertising. In R. Gill, \& C. Scharf, New Femininities (pp. 37-51). London: Palgrave MacMillan. doi:https://doi.org/10.1057/9780230294523_3

Reischer, E., \& Koo, K. (2004). The Body Beautiful: Symbolism and Agency in the Social World. Annual Review of Anthropology, 33, 297-317.

Steinberg, J. (2015). The Social Construction of Beauty: Body Modification Examined Through the Lens of Social Learning Theory. California: Pacifica Graduate Institute.

Tseelon, E. (1993). The Ideology of Beauty. Recent Trends in Theoretical Psychology, 319-323.

Wolf, N. (2013). The Beauty Myth: How Images of Beauty are Used Against Women. London: Vintage Digital. 